\title{
Community-based Study of Contraceptive Behaviour in Nigeria
}

\author{
Boniface A. Oye-Adeniran 1,7, Isaac F. Adewole, ,7, Augustine V. Umoh', Adesina Oladokun² Abidoye Gbadegesin', \\ Ekanem E. Ekanem ${ }^{5}$, Bidemi Yusuf', Kofo A. Odeyemi ${ }^{5}$, Ngozi Iwere and Pat Mabmoud
}

\begin{abstract}
A cross sectional, community-based, descriptive study among women of reproductive age group (15-49 years) in Nigeria to explore the possible reasons for contraceptive non-use despite reported high awareness was carried out. Data were obtained using a standard questionnaire instrument and applied on 2001 respondents. Contraceptive prevalence among sexually active respondents was $14.8 \%$ for all methods, $10.1 \%$ for modern methods and only $0.8 \%$ for emergency contraceptives. The most frequently stated reasons for non-use of contraceptives, among those who had never used any contraceptives but who did not want more children were: "did not think about it", "against religious belief" and "fear of side effects." Prior counseling significantly improved the continuation rate of contraception. Multivariate analysis showed that older, married and more educated women tended to use contraceptives more. Health-care providers should be trained to offer counseling services to all clients in general, and young, unmarried and uneducated women in particular in order to improve their acceptance of contraceptives. (Rev Afr Santé Reprod 2006; 10[2]:90-104)
\end{abstract}

\section{RÉSUMÉ}

Une étude à base communautaire sur le comportement du contraceptif au Nigéria. Nous avons mené une étude descriptive traversale à base communautaaire auprès des femmes dans le group en âge d'avoir des enfants (1519 ans) au Nigéria afin d'explorer les raisons qui peuvent expliquer le non-usage des contraceptifs malgré le haut niveau de sensibilisation. Les données ont été recueillies à l'aide d'un instrument de questionnaires standards administrés aux 2001 répondantes. La fréquence contraceptive parmi les répondants qui sont sexuellement actives était de $14,8 \%$ pour toutes les méthodes, $10,1 \%$ pour les méthodes modernes et juste $0,8 \%$ pour les contraceptifs d'urgence. Les raisons les plus fréquemment données pour expliquer le non-usage des contraceptifs parmi ceux qui n'ont jamais utilisé les contraceptifs, mais qui ne voulaient pas encore d'enfants étaient: "je n'y ai pensé", "contre la croyance religieuse" et "la peur des effets secondaires". L'analyse multifactorielle a montré que les femmes les plus âgées, mariées et instruites avaient la tendance d'utiliser les contraceptifs. Il faut former des prestataires de services médicaux pour qu'ils puissent rendre les services d'orientation à tous les clients en général, mais sourtout aux jeunes, aux célibataires et aux femmes non-instruites afin d'améliorer leur acceptance des contraceptifs. (Rev Afr Santé Reprod 2006; 10[2]:90-104)

\footnotetext{
KEY Words: Community based study, Contraception, Contraceptive prevalence, family planning, Nigeria.

${ }^{1}$ Department of Obstetrics \& Gynaecology, College of Medicine, University of Lagos (CMUL), Lagos, Nigeria. ${ }^{2}$ Department of Obstetrics \& Gynaecology, College of Medicine, University of Ibadan, Ibadan, Nigeria. ${ }^{3}$ Department of Obstetrics \& Gynaecology, College of Health Sciences, University of Uyo, Uyo, Nigeria. ${ }^{4}$ Department of Obstetrics \& Gynaecology, Ayinke House, Lagos State University Teaching Hospital (LASUTH), Ikeja, Lagos, Nigeria. ${ }^{5}$ Department of Community Health, College of Medicine, University of Lagos (CMUL), Lagos, Nigeria. ${ }^{6}$ Department of Epidemiology, Medical Statistics \& Environmental Health, College of Medicine, University of Ibadan, Ibadan, Nigeria. ${ }^{7}$ Coordinator, The Campaign Against Unwanted Pregnany (The CAUP)

Correspondence: Boniface A. Oye-Adeniran, Department of Obstetrics \& Gynaecology, College of Medicine, University of Lagos (CMUL), Lagos, Nigeria. E-mail:bonifaceoye@yahoo.com Cc: oye@,beta.linkserve.com
} 


\section{Introduction}

Contraception has been identified as an effective means of combating the problem of unwanted pregnancy and unsafe abortion ${ }^{1}$. It is equally an effective means of family planning and fertility control and therefore very important in promoting maternal and child health. The barrier methods are also useful in the prevention and control of sexually transmitted infections (STIs) including HIV/AIDS. In the developing world in general and Nigeria in particular unwanted pregnancy, unsafe induced abortion, high fertility rates, high maternal mortality rates, STIs and HIV/AIDS are all very serious reproductive health problems that require urgent attention ${ }^{1-10}$. Unsafe abortion is a major cause of maternal morbidity and mortality accounting for as much as $22.5-40 \%$ of maternal deaths ${ }^{5,9}$. As many as 610,000 abortions are estimated to be performed annually in Nigeria $^{2}$, and 46 million annually worldwide ${ }^{7}$. High fertility rate in the face of dwindling and mismanaged resources has also been a contributor to poverty in most developing world. It is contended that no community can rise out of destitution to dignity in the absence of family planning ${ }_{11}$ and sound resource management.

The contraceptive prevalence in most developing countries remains very low ${ }^{8}$. Worldwide contraceptive prevalence was estimated at 55\% in 20028. In Nigeria it ranges between $5-15 \%{ }^{8,12-14}$. This is in spite of a high awareness of contraception reported in the country ${ }^{5,14-17}$. Studies from Jos and Ife reported awareness by $90 \%$ of all respondents of modern methods of contraception ${ }^{5}$. In a study from Lagos, $95.2 \%$ of women sampled knew about some modern contraceptive methods yet the unmet need amongst them was estimated at $87.2 \%{ }^{15}$. Similarly in a survey of undergraduates in South-Western Nigeria $87.5 \%$ were found knowledgeable about contraception, $87 \%$ were sexually active but only $34.7 \%$ were current users of modern contraceptive methods ${ }^{16}$. The Nigeria
Demographic and Health Survey, (NDHS) 2003 showed that $76.7 \%$ of women had knowledge of modern contraceptive methods but the contraceptive prevalence for modern methods among them was only $8.9 \%{ }^{14}$

The consistent discovery of the disparity between awareness of contraception and its use informed this study with the aim of determining the prevalence of contraception at community level as well as elucidating the possible factors that lead to the high level of non-use of contraception in Nigeria. It is hoped that understanding these factors might assist to promote increased use of contraception in Nigeria.

\section{Methodology}

\section{Study Population}

This study was undertaken in both urban and rural communities (as defined by the National Population Commission) selected from the then four Health Zones of the country. We decided to use the four health zones rather than the six political zones because most of the planning on and implementation of public health programmes in Nigeria are mostly based on the former rather than the later. Respondents were women aged 15-49 years, generally accepted as women in the reproductive age group.

\section{Study Design and Sample Size}

This study was primarily descriptive in nature. The aim was to estimate any given population parameter (e.g., contraceptive prevalence, contraceptive ever use, etc.) with a specified level of precision and confidence. The level of confidence was specified as $95 \%$ and the tolerable error margin was $5 \%$. Several specifications of $\boldsymbol{p}$ (estimated prevalence) were made based on the study objectives. The largest sample size, which satisfied all objectives were, based on the estimated contraceptive ever use rate of $30 \%$. The sample size expression for cross-sectional descriptive studies: $n=Z 2(100-p) p / \delta^{2}$ was used and a 
sample size of 323 respondents from each zone was needed. The sample size was adjusted further to compensate for non-response rate of $20 \%$ thus the final minimum sample size was 480 .

\section{Selection of Respondents}

Four States, were randomly selected for the study, one each from the four health zones - Anambra from Health Zone A in the Southeast, Oyo from Health Zone B in the Southwest, Kaduna from Health Zone C in the Northwest and Bauchi from Health Zone D in the Northeast. A multi-stage cluster sampling design was employed to select the respondents. In each health zone, two local government areas (one urban and one rural) were randomly selected. Two hundred and fifty (250) women in the reproductive age group (15-49 years) from each LGA were selected for the survey. Enumeration Areas (EAs) served as the Primary Sampling Unit (PSU) in the LGAs. These are geographic clusters that have been clearly demarcated by the National Population Commission. A systematic sampling approach was used to select ten EAs from each LGA. In each EA, a random starting point was determined in the field by the supervisor using a community landmark such as Village Square, church or a mosque. Eligible respondents were consecutively recruited and interviewed until the required sample size for the selected EA was achieved. Only one eligible respondent was interviewed per household. If a household had more than one eligible respondent, only one was randomly selected. A total of 2001 respondents were interviewed in 2002, and these were fairly evenly distributed between rural and urban areas.

\section{Data Collection and Analysis}

Interviewers were females who were versed in the local language in addition to English and have had previous experience in community-based health-related research. A central training was organized for the interviewers. Training included interviewing techniques, detailed explanation of each of the questions, eligibility and selection of respondents and role-plays. The questionnaire was then pre-tested for comprehensibility, appropriateness of language, sensitivity of questions and average duration for administration. Ethical approval was obtained from the Ethical Committee of the Lagos University Teaching Hospital, Lagos, Nigeria. The interviewers obtained the consent of each respondent.

Data were entered and analysed using Epi Info version 6.0. Frequency tables were generated for relevant variables. Descriptive statistics such as means and standard deviations were used to summarize quantitative variables while qualitative variables were summarised with percentages. Bar diagrams were also used to present qualitative variables. The chi-squared test was used to compare percentages. Multiple logistic regression was used to investigate the relationship between selected independent variables and contraceptive ever use in the first instance and contraceptive non use in the second instance (the dependent variable). Age of the respondent was treated as continuous variable, while religion was treated as dichotomous, where Christianity was coded as 1 and others (mainly Islam) were coded as 0 . Educational level and Occupation were treated as ordinal variables. Marital status was reconstructed as dichotomous variable where "unmarried" coded as 1 and married were coded as 0 . All analyses were carried out at the $5 \%$ level of significance.

\section{Results}

Most of the respondents, $67.4 \%$ interviewed in the sample were married. This was followed by those that were single, $26.1 \%$. Very few of the respondents were widowed, $3.2 \%$, divorced $1.5 \%$, separated $1.0 \%$ or living together with a partner $0.7 \%$. About two thirds, $61.1 \%$, of all the married respondents were from monogamous families.

African Journal of Reproductive Health Vol. 10 No.2 August 2006 
Table 1: Percentage distribution of the Socio-demographic characteristics of the respondents by Health Zone

\begin{tabular}{|c|c|c|c|c|}
\hline \multirow[b]{3}{*}{ South West } & \multicolumn{3}{|c|}{ HEALTH ZONE } & \multirow[b]{4}{*}{$n=497$} \\
\hline & South East & North East & North West & \\
\hline & & & & \\
\hline Age Category & $n=500$ & $n=499$ & $n=498$ & \\
\hline $15-19$ & 20.6 & 17.0 & 25.7 & 15.3 \\
\hline $20-24$ & 21.4 & 22.2 & 24.1 & 20.5 \\
\hline $25-29$ & 11.4 & 16.8 & 17.3 & 19.3 \\
\hline $30-34$ & 11.0 & 17.8 & 11.8 & 15.9 \\
\hline $35-39$ & 13.6 & 15.0 & 8.6 & 12.7 \\
\hline \multirow[t]{2}{*}{$40-49$} & 22.0 & 11.0 & 12.5 & 16.3 \\
\hline & Religion & $\mathrm{n}=500$ & $\mathrm{n}=500$ & $n=500 n=501$ \\
\hline Catholic & 59.2 & 6.8 & 7.4 & 2.8 \\
\hline Islam & 0.0 & 85.6 & 73.2 & 30.9 \\
\hline Traditional & 0.2 & 1.0 & 0.2 & 0.2 \\
\hline Protestant & 26.0 & 5.4 & 10.4 & 36.1 \\
\hline Pentecostal & 13.8 & 1.0 & 4.2 & 22.4 \\
\hline Spiritual & 0.8 & 0.0 & 0.2 & 4.2 \\
\hline Others & 0.0 & 0.0 & 2.8 & 2.6 \\
\hline No Religion & 0.0 & 0.0 & 0.0 & 0.8 \\
\hline \multirow[t]{2}{*}{ No Response } & 0.0 & 0.2 & 1.6 & 0.0 \\
\hline & Marital Status & $\mathrm{n}=489$ & $\mathrm{n}=498$ & $\mathrm{n}=475 \mathrm{n}=488$ \\
\hline Single & 39.3 & 5.4 & 31.8 & 28.5 \\
\hline Married & 53.4 & 91.2 & 62.7 & 61.9 \\
\hline \multicolumn{5}{|l|}{ Living together with a } \\
\hline partner but not married & 1.0 & 0.4 & 0.0 & 1.4 \\
\hline Separated & 0.6 & 0.4 & 0.6 & 2.5 \\
\hline Divorced & 0.2 & 1.2 & 2.7 & 2.0 \\
\hline \multirow[t]{2}{*}{ Widowed } & 5.5 & 1.4 & 2.1 & 3.7 \\
\hline & Education & $n=500$ & $\mathrm{n}=495$ & $n=491 n=480$ \\
\hline No formal Education & 5.4 & 52.5 & 33.0 & 15.0 \\
\hline Part Primary & 7.6 & 16.2 & 8.2 & 6.3 \\
\hline Primary & 14.8 & 12.5 & 13.6 & 21.7 \\
\hline Part Secondary & 28.4 & 3.2 & 13.0 & 16.0 \\
\hline Secondary & 33.2 & 8.5 & 18.0 & 19.6 \\
\hline University Graduate & 2.4 & 0.4 & 0.2 & 4.2 \\
\hline Others (specify) & 8.2 & 6.7 & 12.0 & 17.3 \\
\hline
\end{tabular}

The age distribution of respondents in the four Health Zones is shown in Figure 1. The mean age of the respondents was 28.2 years $(S D=9.17)$.

There was a significant difference $(\mathrm{p}<0.01)$ in the educational status of the respondents in the four Health Zones. In the southeast, $33.2 \%$ of the respondents had completed secondary education followed by those, $28.4 \%$, who had part secondary education. $52.5 \%$ of the respondents in the Northeast and $33 \%$ in the Northwest had no African Journal of Reproductive Health Vol. 10 No.2 August 2006 formal education. In the southwest, $21.7 \%$ had completed primary education followed by those $19.6 \%$ who had completed secondary education. The level of education of respondents in urban areas was significantly $(p<0.05)$ higher than those in the rural areas. The predominant religion in the Northern states of the study was Islam while in 


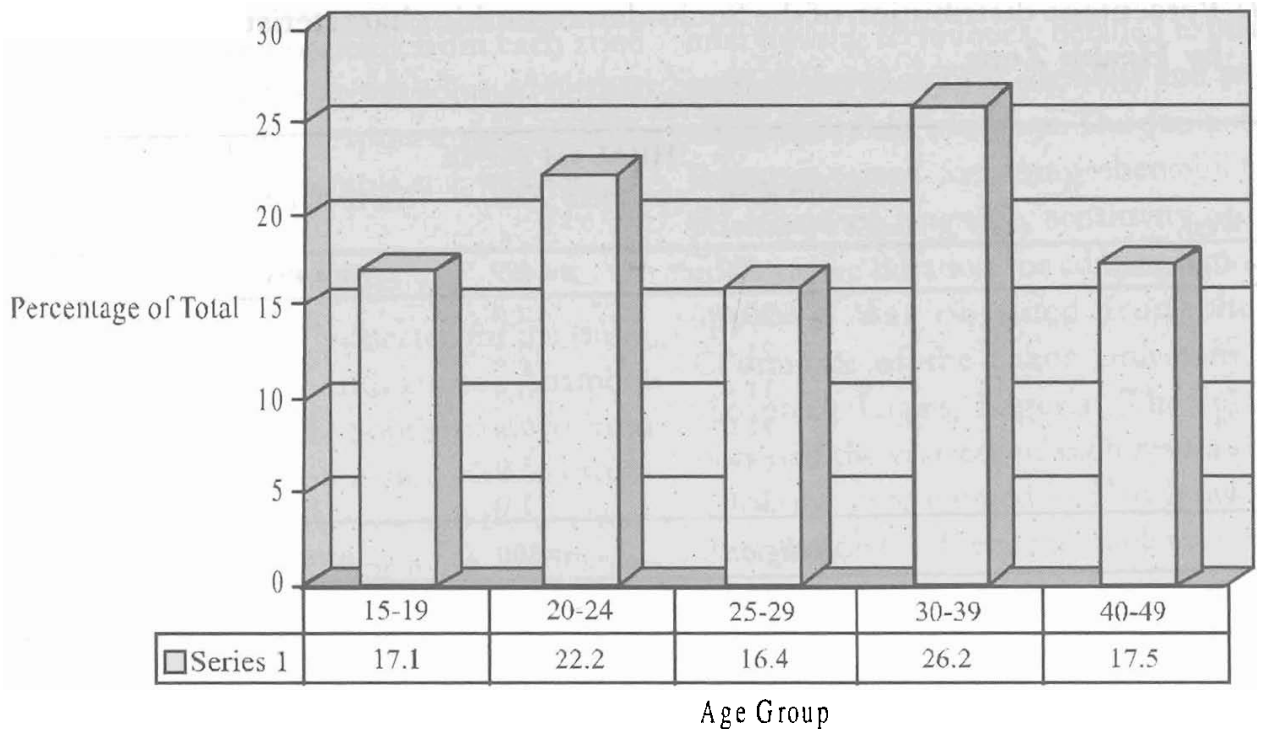

Figure 1: Age Distribution of Respondents

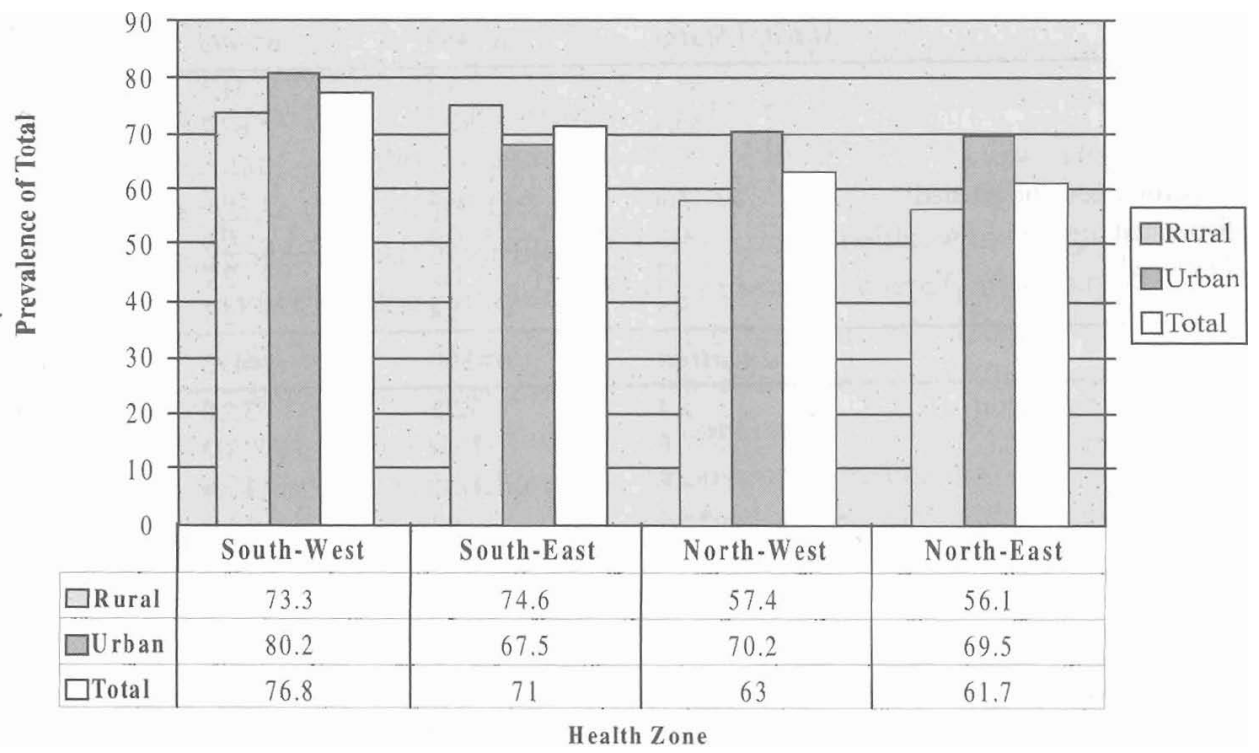

Figure 2: Percentage of respondents who are aware of any method of contraception by Health Zone and Locality

the Southern states it was Christianity. In the Southeast, $59.2 \%$ of the respondents were Catholics.

\section{Contraceptive Awareness}

A total of 1342 of the 2001 respondents had heard of ways that women or men can use to 
delay or avoid getting pregnant giving an awareness of $67.1 \%$. The gradient flow of awareness is as follows: Southwest $76.8 \%$, Southeast $71 \%$, Northwest $63 \%$ and Northeast $61.7 \%$. Respondents in the urban areas knew more about contraception (72.1\%) than their rural counterparts $(64.8 \%)$ although the difference was not statistically significant $(p>0.05)$

The methods of contraception that most of the respondents in the rural areas have heard of were: pill, $(24.7 \%)$, injectables $(22.7 \%)$, IntraUterine Device (IUD), (16.7\%) and condom, $(12.2 \%)$. In urban areas, the methods they have heard were: pill, $(32.3 \%)$, condom $(28.1 \%)$, - injectables, $(28.2 \%)$ and IUD, (18.5\%). Male sterilization was the method least known both in rural and urban areas. The Southwest had the highest percentage of respondents, $39.2 \%$ who have heard of use of condoms as a method of preventing or delaying pregnancy; while the Northeast had the lowest (8.1\%).

In the rural areas, the respondents got to know about the methods of contraception mostly from nurses, $35.1 \%$; radio, $28.3 \%$; and friends, $22.3 \%$. In urban areas, the respondents got their information mostly from friends, $43.7 \%$; nurses, $36.8 \%$ and radio, $30.1 \%$. Only $0.3 \%$ of the respondents in rural areas and none, $0.0 \%$, in urban areas knew from their fathers; while $5 \%$ had information from their mothers. Other sources of information on contraception that were mentioned by the respondents included spouses, church meetings, health educators, and organized women associations. In the Southeast, the popular women August meeting was frequently mentioned.

\section{Contraceptive Usage}

Of the 2001 respondents, only 441 (22.1\%) had ever used a contraceptive. Among those who had heard of ways of preventing or avoiding pregnancy only $32.9 \%$ had used a method. Specifically, among those who have known about contraception, $73.7 \%$ in Southeast, $64.2 \%$ in Northeast, $58.1 \%$ in Northwest and $53.5 \%$ in Southwest had never used or tried any method. Ever use of contraception was slightly higher among urban respondents than among their rural counterparts even though there was a higher percentage of sexually active youths (15-24 years) in rural than urban areas. (Figure 3)

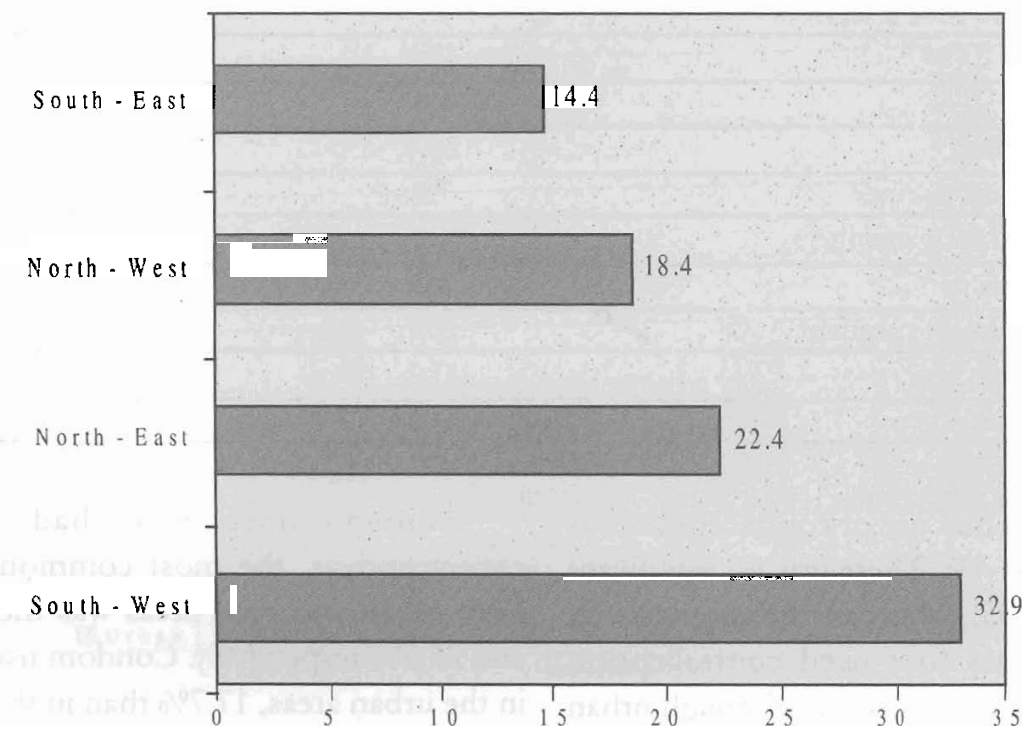

Figure 3: Contraceptive ever use rate (\%) by Health Zone 
Table 2: Sources from where respondents got to know about contraceptives by locality

\begin{tabular}{|c|c|c|c|c|c|}
\hline \multicolumn{6}{|c|}{ Locality } \\
\hline Source & Rural & Urban & Total & $\mathbf{X}^{2}$ & p-value \\
\hline & 678 & 655 & 1342 & & \\
\hline Friends & 22.3 & 43.4 & 32.6 & 67.9 & $<0.001$ \\
\hline Neighbours & 7.3 & 6.9 & 7.1 & 0.08 & 0.771 \\
\hline Relations & 1.5 & 2.4 & 1.9 & 1.72 & 0.190 \\
\hline Father & 0.3 & 0.0 & 0.1 & 1.91 & 0.170 \\
\hline Mother & 5.5 & 3.7 & 4.6 & 2.67 & 0.103 \\
\hline Sibling & 0.1 & 1.4 & 0.7 & 6.84 & 0.009 \\
\hline Doctor & 3.3 & 9.5 & 6.3 & 21.15 & $<0.001$ \\
\hline Nurse & 35.1 & 34.0 & 34.6 & 0.16 & 0.690 \\
\hline Teacher & 4.4 & 6.9 & 5.6 & 3.98 & 0.046 \\
\hline Pastor & 1.7 & 0.8 & 1.3 & 2.59 & 0.107 \\
\hline Radio & 28.1 & 28.9 & 28.5 & 0.10 & 0.757 \\
\hline TV & 3.3 & 12.8 & 8 & 41.14 & $<0.001$ \\
\hline Newspaper & 1.3 & 6.0 & 3.6 & 20.97 & $<0.001$ \\
\hline
\end{tabular}

One bundred and forty-nine (149) respondents indicated other sources, out of which women's August meeting was indicated by $18.1 \%$ of rural respondents and $13.6 \%$ of the urban.

\section{Table 3: Percentage distribution by reasons for non-use by respondents}

\begin{tabular}{|lcc|}
\hline Reasons & Never Used & Current Non-Use \\
\hline Wanted more children & 8.4 & 36.3 \\
\hline Didn't know where to get FP services & 4.7 & 1.1 \\
\hline Fear of side effects & 13.8 & 10.2 \\
\hline Health reasons & 1.6 & 1.3 \\
\hline Against religious belief & 20.4 & 10.3 \\
\hline Objection of husband/partner & 7.9 & 6.4 \\
\hline Objection of other family members & 1.0 & 0.8 \\
\hline Cannot afford the price & 0.2 & 0.5 \\
\hline Do not think I would get pregnant & 9.3 & 6.3 \\
\hline Do not expect to have sex & 11.2 & 10.6 \\
\hline Do not think about it & 21.6 & 15.3 \\
\hline
\end{tabular}

The median age at first use of contraception was 23 years (range 11-44). There was no significant difference, $(p>0.05)$, between the mean age at which respondents first used contraception among urban and rural dwellers although urban dwellers seemed to start slightly earlier than those users in rural areas.
Among those who had ever used contraceptives, the most common method in both urban and rural areas was the pill, 30.3\% and $26.5 \%$ respectively. Condom use was higher in the urban areas, $17.7 \%$ than in the rural areas, $8.8 \%$ while traditional methods were used more by respondents in the rural areas, $12.4 \%$ than

African Journal of Reproductive Health Vol. 10 No.2 August 2006 
those in urban areas, $3.3 \%$. The least used method was male sterilization: rural $0.0 \%$, urban $0.4 \%$. Condom use was more in the Southeast and least, $1 \%$, in the Northeast.

Of the 390 respondents who provided information on decision to first use contraception, $44.6 \%$ indicated self, $23.6 \%$ indicated husband/ partner while $16.1 \%$ indicated joint decision. Among the remaining $15.7 \%$, the decision to use contraception was taken by friends, health workers and other family members (but not fathers).

At the first use of contraception, 16.4\% procured them from chemist/patents medicine shops, $11.1 \%$ procured them from Health Centres, $0.8 \%$ from Family Planning Centres, while $13.9 \%$ got them from general hospitals. At the place of procurement, both the client and partner largely made choice of the specific method. Service providers rarely made the choice of method.

Nearly two thirds $(61.5 \%)$ of the respondents were counselled at the place of procurement and a nurse in most of the cases provided the counselling service. Among those who had stopped using a method, the most common reasons given were that they had got married and among the already married ones, they now wanted more children.

Of the 2001 respondents, 244 were currently using contraceptive method. Of this number, 166 were using modern contraceptive methods. Contraceptive use was highest in the southwest $(22.4 \%)$ and lowest in the Northwest (8.2\%). Current contraceptive use was consistently and statistically higher in urban areas than in the rural $(14.6 \%$ vs. $10.1 \%)$.

Because the risk of pregnancy is only among those who are sexually active, contraceptive use was further evaluated among this subgroup. 1647 respondents were sexually active giving an overall contraceptive prevalence of $14.8 \%$ for all methods and $10.1 \%$ for modern methods. Contraceptive prevalence in this group was highest among urban respondents in the Southwest and least among ruraledwellers in the Northwest.

The most common sources of information on the methods currently being used were friends $(34 \%)$, radio $(11.5 \%)$ and spouses $(10.2 \%)$.

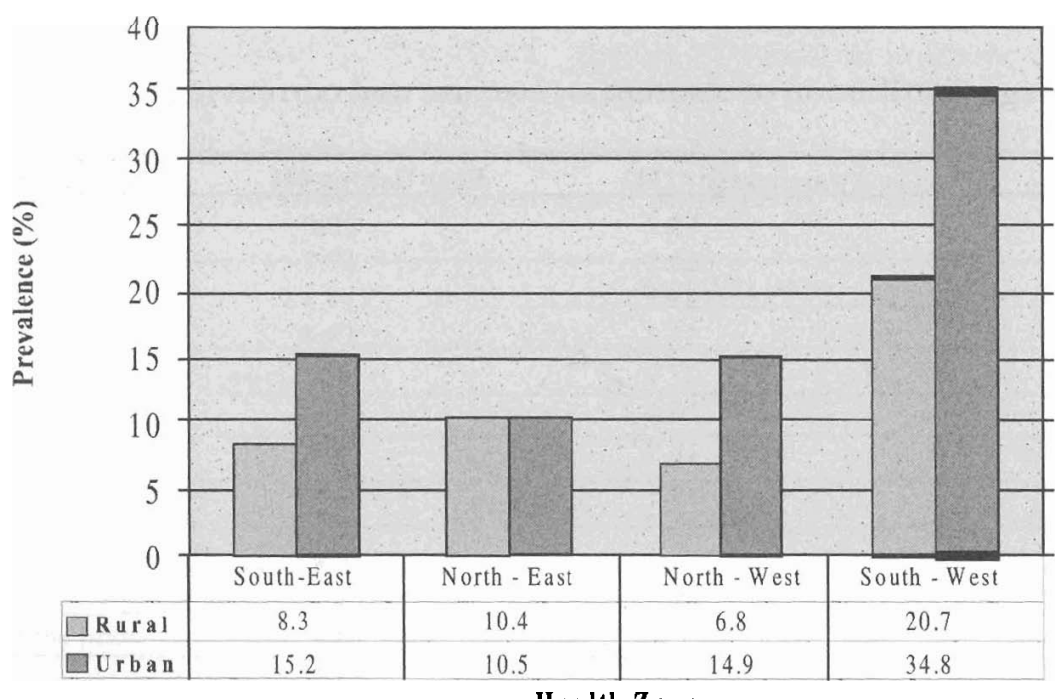

Health Zone 
Among the methods currently used, the most common ones were the IUD (18.4\%), condoms $(18.4 \%)$, injectables $(13.1 \%)$ and the pill $(12.3 \%)$. Traditional methods were mostly used by rural respondents.

Of the 244 respondents who were using contraception at the time of the survey, $84.4 \%$ did so with the knowledge of the husband/ partner. Respondents from the Southwest were less likely to inform their husbands/ partners about current use.

Out of 244 respondents who were currently using a method, $56.6 \%$ were counselled. There was significant difference, $(\mathrm{P}<0.05)$, in whether or not the respondents were counselled at the place of procurement of family planning method in the rural and urban areas. The percentage of respondents, $59.6 \%$ who were counselled in the rural areas were higher than in urban areas, $40.3 \%$. The respondents who were currently using a family planning method were counselled mostly by nurses, $33.6 \%$. The percentage counselled by a doctor was $6.9 \%$. Only few of the respondents were counselled by patent medicine vendor, $0.8 \%$ and traditional healer/herbalist, $1.2 \%$.

The most common consideration in the choice of contraceptive method was its convenience, $34.4 \%$, followed by effectiveness, $18 \%$ and absence of side effects $14.3 \%$. Cost and availability were not major considerations. There was no significant association, $\mathrm{p}>0.05$, between location (rural or urban) of respondents and factor considered most important in choosing a family planning method. There was a statistically significant difference, $\mathrm{p}<0.05$, between respondents who experienced side effects but were aware of the possibility of having them and those that were not, prior to adoption of a family planning method in the four health zones. Of the respondents that were aware of the possibility of side effects as a result of family planning method, before adopting a method most, $71.4 \%$, were informed during family planning counselling; some heard from friends, $9.5 \%$, patent medicine vendor, $4.8 \%$ or read about it, $4.8 \%$.

The decisions to use the current method were largely taken by the respondents and to a lesser extent, the service provider at the place of procurement. Of the 244 respondents that were currently using a method, $88.5 \%$ were satisfied. For those who were not satisfied, the most frequently cited reasons were bleeding (either excessive or spotting), irregular menstrual cycle

Table 4: Percentage distribution of awareness, ever use and current use of different methods

\begin{tabular}{|lccc|}
\hline Method & Awareness $^{*} \mathbf{n}_{\mathbf{1 3 4 2}}$ & Ever Use $_{\mathbf{n}}=\mathbf{4 4 1}$ & Current Use $_{\mathbf{n}}=\mathbf{2 4 4}$ \\
\hline Pill & 65.2 & 28.8 & 12.3 \\
Injectables & 60.2 & 17.0 & 13.1 \\
Condom & 53.7 & 14.3 & 18.4 \\
IUD & 53.3 & 18.4 & 18.4 \\
Rhythm & 27.9 & 7.9 & 15.2 \\
Implant & 20.1 & 1.1 & 1.3 \\
Female Sterilisation & 18.9 & 1.6 & 3.3 \\
Withdrawal & 16.4 & 3.4 & 6.2 \\
Foam & 13.9 & 1.6 & 1.0 \\
Traditional & 13.1 & 6.8 & 7.4 \\
Abstinence & 11.9 & 4.1 & 4.1 \\
Male Sterilisation & 7.4 & 0.2 & 0.0 \\
Breast feeding & 6.6 & 5.4 & 4.1 \\
Emergency Contraceptive & 0.2 & 0.5 & 0.8 \\
Others & 6.9 & 0.7 & 1.2 \\
\hline
\end{tabular}

* Some respondents gave multiple responses. 
and reduced menstrual flow. Among those currently using a method, $15.2 \%$ complained of side effects which included bleeding $25.6 \%$, irregular menstruation, $12.8 \%$, irregular menstrual cycle, $12.8 \%$, abdominal pain, $7.7 \%$, body weakness, $7.7 \%$ and heavy menstrual flow, $5.1 \%$. Others included discomfort during sexual intercourse and waist pain.

Among those who have heard of methods of contraception, 854 respondents had never used any method of contraception. Of this number, $29.2 \%$ had never used a method, because they wanted more children. This was followed by those, who did not think about contraception $14.6 \%$ and those who said it was against their religious beliefs, $13.7 \%$.

In both the rural, $17.8 \%$ and urban areas, $11.1 \%$, majority of the respondents who had never used a family planning method did not because they wanted more children. In the rural areas, some commonly given reasons for not using any method were "against religious belief", $9.8 \%$, "do not think about it", $8.2 \%$, and "fear of side effects", $5.6 \%$. In the urban areas reasons for not using family planning methods were: "do not think about it", 6.4\%; "do not think I would get pregnant", $5.7 \%$ "did not expect to have sex", $4.6 \%$, and "against religious belief", 3.9\%. None of the respondents in the rural areas attributed the non-use of a family planning method to cost.

\section{Reasons for Discontinuation}

The reason(s) for discontinuing their choice of family planning method are similar to the reasons adduced for never using a method to prevent pregnancy.

Of the respondents who had used a family planning method but are not currently using a method, most, $61.7 \%$ wanted more children, followed by those, $17.9 \%$ who did not expect to have sex and $17.2 \%$ that were afraid of side effects. The reasons for discontinuation of the methods were similar in both urban and rural areas. Of those who were using a method but stopped, $54.6 \%$ intend to use it again in future whereas among those 854 who have never used a method, $42.7 \%$ intend to use it later. There was a significant difference, $\mathrm{p}<0.05$, in the proportion of respondents intending to resume the use of a family planning method and the health zones they were in. Majority of the respondents in the Northeast, $26.3 \%$, and Southwest, $32.5 \%$ had the intention of resuming the use whereas majority of the respondents those in Southeast, 28.9\% and Northwest $32.6 \%$ had no intention to resume the use of a method in future.

Table 5: Percentage distribution of the reasons for non-use among those who were aware of contraception and do not want more children $[n=607]$

\begin{tabular}{|c|c|c|c|}
\hline \multirow[t]{2}{*}{ REASONS } & \multicolumn{2}{|c|}{ LOCATION } & \multirow[b]{2}{*}{ Total } \\
\hline & Rural & Urban & \\
\hline Do not know where to get FP services & 2.2 & 6.5 & 4.3 \\
\hline Fear of side effects & 13.7 & 11.6 & 12.7 \\
\hline Health Reasons & 0.6 & 2.4 & 1.5 \\
\hline Against religious belief & 26.8 & 35.1 & 19.3 \\
\hline Objection of husband/partner & 8.9 & 6.1 & 7.6 \\
\hline Objection of other family members & 0.9 & 0.7 & 0.8 \\
\hline Cannot afford the price & 0.0 & 0.3 & 0.2 \\
\hline Do not think I would get pregnant & 1.3 & 16.3 & 8.6 \\
\hline Do not expect to have sex & 8.3 & 12.6 & 10.4 \\
\hline Do not think about it & 20.1 & 20.7 & 20.4 \\
\hline Others & 16.9 & 11.6 & 14.3 \\
\hline
\end{tabular}

African Journal of Reproductive Health Vol. 10 No.2 August 2006 
There was no significant difference, $\mathrm{p}>0.05$, between the intention of respondents to resume the use of a family planning method and their location (rural or urban). Most of the respondents in both urban, $54.6 \%$ and rural $45.4 \%$ areas had the intention to resume the use of a method in future. A higher percentage of respondents, $41.8 \%$ in rural areas then in urban areas, 58.2\% were not sure of resuming the use of a method in future.

\section{Contraceptive Failure}

Of the 263 respondents who were pregnant when they did not want to, $22.1 \%$ were using a family planning method. In urban areas, majority of respondents who had unwanted pregnancy,
$6.1 \%$ were using pill. Some of the others were using rhythm/periodic abstinence, $4.6 \%$, or withdrawal methods $2.3 \%$. In rural areas, majority of respondents who had unwanted pregnancy were either using pills, $3.0 \%$ or traditional methods, $2.3 \%$. ome others were using IUD, $1.1 \%$, rhythm/periodic abstinence, $1.1 \%$ or injectables, $1.1 \%$.

None of the respondents, who had unwanted pregnancy in Northeast and Northwest, was using condom as a pregnancy preventive method. Generally, majority of the respondents who had unwanted pregnancy and who were not using any family planning method did not because; they did not think they would get pregnant.

Table 6: Multiple Unconditional Logistic Regression Analysis of the relationship between selected independent variables and contraceptive ever use

\begin{tabular}{|lcccc|}
\hline Variables & $\begin{array}{l}\text { Regression } \\
\text { Coefficient }\end{array}$ & Odds Ratio & 95\%CI & p-value \\
\hline $\begin{array}{l}\text { Age } \\
0.001\end{array}$ & 0.0361 & 1.0368 & 1.0145 & -1.0596 \\
\hline $\begin{array}{l}\text { Marriage } \\
0.004\end{array}$ & -0.8454 & 0.4294 & 0.2426 & -0.7601 \\
\hline $\begin{array}{l}\text { Education } \\
<0.001\end{array}$ & 0.3072 & 1.3596 & 1.2603 & -1.4667 \\
\hline $\begin{array}{l}\text { Occupation } \\
0.453\end{array}$ & 0.0179 & 1.0180 & 0.9715 & -.0668 \\
\hline $\begin{array}{l}\text { Parity } \\
0.051\end{array}$ & 0.0605 & 1.0623 & 0.9998 & -1.1288 \\
\hline $\begin{array}{l}\text { Religion } \\
0.084\end{array}$ & -0.2678 & 0.7650 & 0.5646 & -.0367 \\
\hline
\end{tabular}

Note that the variables that were significantly related to current use are also significant with ever use.

Table 7: Logistic Regression analysis of the relationship between selected independent variables and contraceptive non-use

\begin{tabular}{|c|c|c|c|c|}
\hline Variables & $\begin{array}{l}\text { Regression } \\
\text { Coefficient }\end{array}$ & OR & $95 \% \mathrm{CI}$ & p-value \\
\hline Age & 0.059 & 1.06 & $1.03-1.09$ & 0.001 \\
\hline Education & 0.320 & 1.40 & $1.3-1.5$ & 0.001 \\
\hline Religion & 0.180 & 1.30 & $0.83-1.72$ & 0.330 \\
\hline Occupation & 0.029 & 1.20 & $0.97-1.09$ & 0.315 \\
\hline Parity & 0.001 & 1.00 & $0.94-1.07$ & 0.989 \\
\hline Marriage & 0.276 & 0.76 & $0.62-0.93$ & 0.007 \\
\hline
\end{tabular}


The logistic regression analysis was applied with age, education, religion, occupation parity and marriage as the independent variables against contraceptive non-use as the dependent variable. The regression model revealed age $(\mathrm{OR}=1.06$; $95 \% \mathrm{CI}=1.03-1.09)$, education $(\mathrm{OR}=1.40$; $95 \% \mathrm{CI}=1.3-1.5)$, and marital status (OR = 0.76 ; $95 \% \mathrm{CI}=0.62-0.93)$ to be strongly and independently associated with contraceptive nonuse. The older, more educated and married women are more likely to use contraceptives.

\section{Discussion}

The awareness of contraception in this study is $67.1 \%$. This is similar to $65 \%$ reported about two decades ago from Benin City in Southwestern Nigeria in $1986^{11}$ but is lower than the 1987 report form Lagos $(95.2 \%)^{15}$, or more recent reports from Jos and Ife $(90 \%)^{5}$, Enugu in Southeastern Nigeria $(81.7 \%)$ 17, among undergraduates in south-western Nigeria $(87.5 \%)^{16}$, and the Nigeria Demographic and Health Survey, (NDHS) 2003 finding $(78.5 \%)^{14}$. Contraceptive awareness has always been noted to be higher in the Southwestern Nigeria14 and in this study also, the Southwestern part of the country had the highest awareness rate with more people being aware in the urban $(72.1 \%)$ than the rural $(64.8 \%)$ areas. It is probable that the lower awareness rate recorded in this study was as a result of some laxity in the pursuit of family planning programs especially with the slowing of efforts in ensuring the working of the Primary Health Care (PHC) and Maternal and Child Health (MCH) programs in Nigeria for some years now. Thankfully, it is one area, which the current health sector reform in the country aims to address. Another surprise finding was the low awareness of condom. This is against the wide advocacy given it due to its importance in the prevention of HIV/AIDS. It is probable that many now see it more in the light of its anti HIV value rather than its contraceptive value.

African Journal of Reproductive Health Vol. 10 No.2 August 2006
The reduction in contraceptive awareness portends a danger because of an apparent loss in gains made in the population and family planning programs in the 80 s and 90s. A study of contraceptive usage among abortion care seekers had made a similar observation of lack of awareness and poor knowledge of contraceptive methods by seekers1. There is therefore a dire need to redouble efforts at improving the awareness of contraception. The main sources of information in both rural and urban areas were nurses, radio and friends. It is necessary to ensure dissemination of correct and appropriate information through these media in order to be certain that same passes to the end users. Friends and other peer groups have been consistently shown to be sources of information on reproductive health issues especially among young persons ${ }^{18-20}$ and abortion care seekers ${ }^{1}$. It is necessary that these groups of people are especially targeted in awareness campaigns as a contraceptive wise adolescent would grow to be reproductive health wise adult.

Contraceptive prevalence in this study was $14.8 \%$ among sexually active respondents. This is within the national range of $5-15 \%{ }^{12}$, but much lower than reported in other studies - Enugu in southeastern part of the country $20 \%{ }^{17}$, among undergraduates in southwestern Nigeria $34.2 \%{ }^{16}$ and among abortion care seekers in same region of Nigeria ${ }^{1}$. A reduction in the number of bilateral tubal ligation acceptors has also been reported from Lagos ${ }^{21}$. The total estimated unmet need for contraception was $62.5 \%$ in this study. This is very high in a country where unsafe abortion with its consequences is a serious problem. While contraceptive awareness was about the same among urban and rural dwellers, the prevalence was higher in the urban areas. It is no surprise therefore that rural dwellers had a higher prevalence of unwanted pregnancies in this study. Contraceptive prevalence is also believed to be directly associated with the educational status ${ }^{11,22,23}$. This was the case in this 
study as those in the urban areas were significantly more educated and had a higher contraceptive prevalence than those in the rural areas. This finding may be related to the understanding of the message of contraception during awareness campaigns. It may be necessary therefore to develop special communication strategies to serve these areas during such enlightenment campaigns.

Aside from those who did not use contraception because they wanted more children, the common reasons given for not using any methods were that they did not think about it or that it was against their religion. For sexually active women, this is unfortunate as the risk of unsafe abortion is real and portends a great danger. It is possible that they may not be fully aware of the implications of their action. This creates a need for more effective ways of communicating the message of contraception to the users. Religion has been identified to play a significant role in decision to use contraception ${ }^{17,24,25}$. Muslims tend to have a higher disproval rate for contraceptive use than other religions ${ }^{24}$. But among the Christian fold the Catholic Church disapproves of contraception even though it sanctions family planning. It was therefore not surprising that the more predominantly Catholic in the southeastern region had the most respondents who had religion as either reason for contraceptive non-usage. A good starting point may be advocacy with clerics, especially Moslem clerics, to convince their adherents that contraception is beneficial to them and to explore possible areas of common ground among those with dogmatic disapproval of contraception.

Other reasons adduced were fear of side effects, 'Did not think I would get pregnant' and 'Did not expect to have sex'. Instructively none of the respondents in both the urban and rural areas in any of the regions attributed non-usage of contraceptive method to cost. The fear of side effects is a recurring issue in contraceptive use/non use $e^{1,5-7,9,11,12,15,16,26-29}$. Proper counselling is necessary to allay these fears for those who come forward, and inclusion of appropriate messages to address this issue during information dissemination and contraceptive awareness campaigns. Provision of leaflets at sources of commodity procurements has also been suggested $_{16}$.

Major factors, which influenced the choice of contraceptives for users, were convenience and effectiveness. It is therefore logical to assume that where the users are offered a range of commodities that are effective and convenient, usage is likely to increase. One-method family planning programs are likely to be inadequate and poorly patronized.

Among those who were currently using contraception, $88.5 \%$ were satisfied with the method. Even though some experienced a few side effects, they received prior counseling. Such measures help to counter the dread of side effects.

Perceived low risk of pregnancy had been reported as an important factor by women who had never used contraceptives in a study from China $^{30}$. A study of adolescents in Ilorin, Nigeria also revealed that young people lacked awareness of the risk of pregnancy, as they believed that one must have sexual intercourse several times before conception can occur ${ }^{31}$. In this study many women also did not think about contraception at all or consider that they may get pregnant even though they were sexually active. This lack of awareness has to be addressed with proper sexuality education. The low contraceptive prevalence of $18.4 \%$ tends to explain the high abortion prevalence of $27 \%$ in the community.

In conclusion, contraceptive prevalence continued to be low in Nigeria. There is also a reduced awareness of modern contraceptive methods in this study. The fear of side effects, poor knowledge of the available methods, perceived low risk of pregnancy, low educational status and religious considerations are factors that contribute to contraceptive non-use. There is a need for continued enlightenment on contraceptives focusing particularly on the side effects and how to overcome the fears. Health care providers should be trained to be able to

African Journal of Reproductive Health Vol. 10 No.2 August 2006 
offer counseling services to all clients in order to improve their acceptance of contraceptives. The young persons should be particularly targeted to inculcate early in them a positive attitude towards family planning including the use of Emergency Contraceptive Pills to prevent unwanted pregnancy.

\section{Acknowledgement}

The Ford Foundation and Institute of International Education (IIE), New York, USA supported this research. The findings and conclusions are those of the authors and do not necessarily represent the views of The Ford Foundation and Institute of International Education.

\section{REFERENCES}

1. Adewole I. F., Oye-Adeniran B. A., Iwere N, Oladokun A, Gbadegesin A, Babarinsa A. I. Contraceptive Usage Among Abortion Seekers in Nigeria. West Afr J Med 2002; 21(2):112- 114

2. Henshaw S K, Singh S, Oye-Adeniran B A, Adewole I. F., Iwere N, Cuca Y. P. The Incidence of Induced Abortion in Nigeria. Int Fam Perspec 1998, 24(4); 156 - 164

3. Oye-Adeniran B A, Umoh A V, Nnatu S N N. Complications of Unsafe Abortion and the Need for Abortion Law Reform in Nigeria. Reproductive Health Matters 2002; 10(19): 18 - 21

4. Adewole I F. Trends in Postabortal Mortality and Morbidity in Ibadan, Nigeria. Int J Gynaecol Obstet 1992; 38(2): $115-8$

5. Okonofua F. E. Odimegwu E, Ajabor H. Assessing the Prevalence and Determinants of Unwanted Pregnancy and Induced Abortion in Nigeria. Stud Fam Plan 1999; 30(1): 67-77

6. Archibong E.I Illegal Induced Abortion: A Continuing Problem in Nigeria. Int J Gynaecol Obstet. 1991; 34(2):261 - 265

7. World Health Organization. Safe Abortion: Technical and Policy Guidance for Health Systems. Geneva, WHO 2002

8. Population Reference Bureau. 2003 World Population Data Sheet of the Population Reference Bureau

African Journal of Reproductive Health Vol. 10 No.2 August 2006
9. Emuveyan E E, Agboghoroma O C. Trends in Abortion Related Maternal Mortality in Lagos, Nigeria. Trop J Obstet Gynaecol 14(1): 39 - 41

10. Federal Ministry of Health, Nigeria. A Technical Report on the 2001 National HIV/Syphilis Sentinel Survey in Nigeria. National AIDS/STDS Control Programme, FMOH, 2001;

11. Omu A E, Unuigbe J A. Acceptance of Contraceptive Practice by Grandmultiparae in Benin City, Nigeria. Int J Gynaecol Obstet 1986; 24: 145 150

12. Obisesan K A, Adeyemo A A, Fakokunde BO. Awareness and use of family planning methods among married women in Nigeria. East Afr med J. 1998; 75 (3): 135-8

13. UN System in Nigeria. NIGERIA: Common country assessment. 2001.

14. National Population Commission (NPC), [Nigeria] and ORC Macro. 2004. Nigeria Demographic and Health Survey 2003 (NDHS). Calverton, Maryland: National Population Commission and ORC Macro.

15. Olukoya A. A. Pregnancy Termination: Results of a Community-Based Study in Lagos. Int. J. Gynaecol Obstet 1987, 25: 4 - 46

16. Arowojolu A. O, Ilesanmi A. O, Roberts O. A, Okunola M. A. Sexuality, contraceptive Choice and AIDS Awareness among Nigerian Undergraduates. Afri. J. Reprod. Health ; 2002; 6(2): 60-70

17. Onuzurike B. K. Uzochukwu B. S. C. Knowledge, Attitude and Practice of family Planning Amongst Women in a High Density Low Income Urban or Enugu, Nigeria. Afri. J. Reprod. Health 2001; 5(2): 83-89

18. Aziken M. E, Okonta P. I, Ande B. A.A. Knowledge and Perception of Emergency Contraception Among Female Nigerian Undergraduates. Int. Fam. Plann Perspect. 2003; 29(2): 84-87.

19. Unuigbe I. E, Ogbeide Osafu. Sexual Behaviour and Perception of AIDS Among Adolescent Girls in Benin City, Nigeria. Afri J. Reprod. Health 1999; 3(1): 39 - 44

20. Koster A, Kemp J, Offei A. Utilisation of Reproductive Health Services by Adolescent Boys in the Eastern Region Of Ghana. Afr I Reprod Health 2001; 5(1):40-49 
104 African Journal of Reproductive Health

21. Oye-Adeniran B A, Umoh A V, Ogedengbe O K, Odum C U, Nnatu S N N. Female Surgical Contraception at the Lagos University Teaching Hospital, Lagos Nigeria: A Fiev-Year Review. Nig QtJ Hosp Med 2000; 10(2): 137 - 140

22. Odimegwu C O. Family planning attitudes and use in Nigeria. A factor analysis. Int Fam Planning Persp 1999; 25 (2) 86-91

23. Teresa CM and Fatima J. The impact of women's education on fertility in Latin America, Searching for explanations. International Family Planning Perspectives 1995; 21: 52-57

24. Ibrahim M T, Sadiq A U. Knowledge, attitude, practices and beliefs about family planning among women attending primary health care clinics in Sokoto Nigeria. Nig J med 1999; 8 (4) 154-158

25. Pakistan Demographic \& Health Survey, 199091Ibrahim M T, Sadiq A U. 1999, op. cit. (see reference 29).
26. Otoide V. O. Oronsanye F. Okonofua F. E. Why Nigerian Adolescents Seek Abortion Rather than contraception: Evidence from Focus-Group Discussions. Int. Fam. Plann Perspect. 2001; 27(2): $77-81$

27. Anate M. Factors Influencing Family Planning Use in Ilorin, Nigeria. East Afr Med J 1995; 72: 418-420

28. Bongaarts J, Bruce J. The Causes of Unmet Needs for Contraception and the Social Content of Services. Stud Fam Plann 1995; 26: 57-75

29. Swar-Eldahab A M. Constraints on Effective Family Planning in Urban Sudan. Stud Fam Plann 1993; 24:366-374

30. Wuj Wang L, Rauyanjin O, Good S. Contraceptive use behaviour among never married young women who are seeking pregnancy termination in Beijing. Chin Med J (Engl) 2002; 115 (6): 851-5.

31. Araoye M O. Sex, contraception and fertility among in-school adolescents in Ilorin. J Comm. Med and Pry Health Care 1998; 10:21-31. 